\title{
Coordination polymers of the bis(imidazole) ligand modulated by dicarboxylate ligands: from 2D layer to 3D framework
}

Fei-Fei Yang ${ }^{\mathrm{a}}$, Xiao-Fang Wang ${ }^{\mathrm{a}}$, Xiao-Yang Yu ${ }^{\mathrm{a}, \mathrm{b}}$, Yu-Hui Luo ${ }^{\mathrm{a}}$, Hong Zhang ${ }^{\mathrm{a} *}$

${ }^{a}$ Institute of Polyoxometalate Chemistry, Department of Chemistry, Northeast Normal

University, Changchun, Jilin 130024, P. R. China

${ }^{b}$ College of Chemical and Pharmaceutical Engineering, Jilin Institute of Chemical Technology, Jilin City, Jilin, 132022, P. R. China

* Corresponding author. Tel.: +86-431-85099372; Fax: +86-431-85684009.

E-mail address: zhangh@,nenu.edu.cn; hope20130122@163.com 
Abstract: Three new coordination polymers, $\left[\mathrm{Zn}\left(\mathrm{H}_{2} \mathrm{biim}\right)(\mathrm{pzdc})\right]_{\mathrm{n}} \quad$ (1), $\left[\mathrm{Cd}\left(\mathrm{H}_{2} \text { biim }\right)(\mathrm{pzdc})\right]_{\mathrm{n}}(\mathbf{2})$ and $\left[\mathrm{Cd}\left(\mathrm{H}_{2} \text { biim }\right)_{0.5}(\mathrm{ip}-\mathrm{OH})\right]_{\mathrm{n}}(\mathbf{3})\left(\mathrm{H}_{2}\right.$ biim = 2,2'-biimidazolate, $\mathrm{H}_{2}$ pzdc $=$ 2,3-pyrazinedicarboxylic acid, $\mathrm{H}_{2} \mathrm{ip}-\mathrm{OH}=$ 5-hydroxylisophthalic acid), have been hydrothermally synthesized and characterized by elemental analysis, infrared spectra and X-ray single-crystal diffraction. Complexes $\mathbf{1}$ and $\mathbf{2}$ are isostructural and display two-dimensional (2D) undulated layers with 3-connected $\left(4.8^{2}\right)$ topologies, which are further extended into three-dimensional (3D) supramolecular structures through hydrogen-bonding and $\mathrm{C}-\mathrm{H} \ldots \pi$ interactions. Complex $\mathbf{3}$ is a relatively rare 3D compound, featuring a binodal $(4,5)$-connected $\left(4^{4} \cdot 6^{2}\right)\left(4^{4} \cdot 6^{6}\right)$ topology. A comparison of all the complexes demonstrates that the structural characteristics of the dicarboxylate ligands play a great role in the modulation of the coordination structures. Moreover, their luminescent properties and thermal stabilities were also investigated.

Keywords: Transitional metal complexes; Bis(imidazole) ligand; Carboxylate ligands; Luminescence

\section{Introduction}

Generally speaking, coordination polymers (CPs) are constructed from inorganic nodes (single metal ions, polynuclear metal cluster, SBUs) and organic linkers (polycarboxylate, N-donors, phosphonate and so on) through coordination interactions. They have received considerable attention, not only because of their topological diversities but also for their potential applications in the following fields: catalysis, luminescence, gas adsorption, magnetism [1-10]. Up until now, a variety of 
remarkable CPs have been documented, which include 1D chains or ladders, 2D grids and $3 \mathrm{D}$ porous motifs. However, the modulation of the coordination structure, which is closely related to the chemical environment, is still a significant challenge in the area of crystal engineering. So far, mixed-ligand coordination polymers involving rigid N-donor ligands have been widely constructed [11-15]. Among these rigid $\mathrm{N}$-donor ligands, the 2,2'-biimidazole ( $\mathrm{H}_{2}$ biim) ligand arouses our interest [16-19]. Firstly, as a neutral ligand, the two nitrogen atoms of the imino moieties have a high affinity for coordinating to metals in the chelating or bridging coordination modes. Secondly, the $\mathrm{H}_{2}$ biim ligand can be partly (Hbiim) or fully (biimº ${ }^{2-}$ ) deprotonated. Therefore, it can act as a bridging ligand and form up to four bonds. Thirdly, under the existence of different torsional angles between the imidazole rings, $\mathrm{H}_{2}$ biim may display different conformations, which provide rich structural diversities. Additionally, due to the existence of imidazole rings, the $\mathrm{H}_{2}$ biim ligand can form weak interactions such as hydrogen-bonding, $\pi \ldots \pi$ and $\mathrm{C}-\mathrm{H} \cdots \pi$ interactions. To our best knowledge, the use of $\mathrm{H}_{2}$ biim as a $\mu_{2}$-bridging ligand to construct 3D frameworks is comparatively rare. Only two examples have been reported for polyoxometallates (POMs) [20-21]. On the other hand, multidentate organic carboxylate ligands have been extensively employed in the construction of CPs with diverse structures and excellent properties, not only because of their many types of bridging coordination modes, but also because of their potential function as hydrogen-bonding acceptors and donors [22-25].

In order to explore the influence of dicarboxylate ligands on the tuning of coordination structures, two kinds of dicarboxylate ligands, namely $\mathrm{H}_{2}$ pzdc 
(2,3-pyrazinedicarboxylic acid) and $\mathrm{H}_{2}$ ip-OH (5-hydroxylisophthalic acid), were introduced into the $\mathrm{Cd} / \mathrm{Zn}-\mathrm{H}_{2}$ biim system. Three interesting coordination polymers, $\left[\mathrm{Zn}\left(\mathrm{H}_{2} \text { biim }\right)(\mathrm{pzdc})\right]_{\mathrm{n}}(\mathbf{1}),\left[\mathrm{Cd}\left(\mathrm{H}_{2} \text { biim }\right)(\mathrm{pzdc})\right]_{\mathrm{n}}$ (2) and $\left[\mathrm{Cd}\left(\mathrm{H}_{2} \text { biim }\right)_{0.5}(\mathrm{ip}-\mathrm{OH})\right]_{\mathrm{n}}$ (3) $\left(\mathrm{H}_{2}\right.$ biim $=2,2$ '-biimidazolate $)$, have been successfully synthesized under hydrothermal conditions. Although the three complexes were prepared in a similar way, we found that the different dicarboxylate ligands greatly influence the final structures produced. The structures display a 2D layer to 3D framework transition. In this paper, we report the syntheses, crystal structures, fluorescence properties and thermal stabilities of the three compounds.

\section{Experimental}

\subsection{Materials and physical measurements}

The reagents were purchased commercially and were used without further purification. The ligand $\mathrm{H}_{2}$ biim was prepared according to the literature procedures [26]. Powder X-ray diffraction (PXRD) patterns were collected on a Rigaku Dmax 2000 X-ray diffractometer with graphite monochromatized $\mathrm{Cu}-\mathrm{Ka}$ radiation $(\lambda=$ $0.15418 \mathrm{~nm}), 2 \theta$ ranging from 5 to $50^{\circ}$ with an increment of $0.02^{\circ}$ and a scanning rate of $5^{\circ} \mathrm{min}^{-1}$. IR ( $\mathrm{KBr}$ pellets) spectra were obtained from 4000 to $400 \mathrm{~cm}^{-1}$ using a Perkin-Elmer Spectrum One FT-IR spectrometer. Elemental analyses for C, H and N were performed on a Perkin-Elmer 2400 Elemental Analyzer. Thermogravimetric (TG) analyses were recorded on a Perkin-Elmer Thermal Analyzer at a heating rate of $10{ }^{\circ} \mathrm{C} \mathrm{min}^{-1}$ and a flow rate of $100 \mathrm{~cm}^{3} \min ^{-1}\left(\mathrm{~N}_{2}\right)$. Luminescent spectra were performed on a Cary Eclipse spectrofluorometer (Varian) equipped with a xenon lamp 
and quartz carrier in the solid state at room temperature.

\section{$<$ Insert Scheme 1 $>$}

\subsection{Synthesis of $\left[\mathrm{Zn}\left(\mathrm{H}_{2} \text { biim) }(p z d c)\right]_{n}(\mathbf{1})\right.$}

A mixture of $\mathrm{Zn}\left(\mathrm{NO}_{3}\right)_{2} \cdot 6 \mathrm{H}_{2} \mathrm{O}(0.1 \mathrm{mmol}, 30 \mathrm{mg}), \mathrm{H}_{2}$ biim $(0.1 \mathrm{mmol}, 13 \mathrm{mg})$, $\mathrm{H}_{2}$ pzdc $(0.1 \mathrm{mmol}, 20 \mathrm{mg})$ and $\mathrm{H}_{2} \mathrm{O}(8 \mathrm{~mL})$ was adjusted to $\mathrm{pH} 5.0$ with $0.05 \mathrm{~mol} \mathrm{~L}^{-1}$ $\mathrm{NaOH}$ solution. It was then sealed in a $25 \mathrm{~mL}$ Teflon reactor and heated at $150{ }^{\circ} \mathrm{C}$ for $72 \mathrm{~h}$. Finally the mixture was cooled to room temperature at a cooling rate of $3{ }^{\circ} \mathrm{C} \mathrm{h}^{-1}$ and block colorless crystals of $\mathbf{1}$ were obtained by filtration. 1 was washed with distilled water and dried in air. Yield: $47 \%$ based on the $\mathrm{Zn}(\mathrm{II})$ salt. Anal. calcd for

$\mathrm{C}_{12} \mathrm{H}_{8} \mathrm{~N}_{6} \mathrm{O} 4 \mathrm{Zn}$ : C, 39.42; H, 2.21; N, 22.99. Found: C, 39.40; H, 2.20; N, 22.91\%. IR (KBr, cm $\left.{ }^{-1}\right): 3088(w), 2993(w), 2897$ (w), 2777 (s), 1608 (s), 1564 (s), 1536 (s), 1457 (s), 1442 (s), 1359 (m), 1322 (m), 1231 (m), 1204 (s), 1170 (s), 1121 (m), 1107 (m), 1064 (s), 993 (s), 946 (m), 859 (s), 833 (m), 772 (m), 740 (s), 693 (s), 665 (s).

\subsection{Synthesis of $\left[\mathrm{Cd}\left(\mathrm{H}_{2} \text { biim) }(\mathrm{pzdc})\right]_{n}\right.$ (2)}

The preparation of $\mathbf{2}$ was similar to that of $\mathbf{1}$ except that $\mathrm{CdCl}_{2} \cdot 2.5 \mathrm{H}_{2} \mathrm{O}(0.1 \mathrm{mmol}$, $30 \mathrm{mg}$ ) was used instead of $\mathrm{Zn}\left(\mathrm{NO}_{3}\right)_{2} \cdot 6 \mathrm{H}_{2} \mathrm{O}$. Block colorless crystals of 2 were obtained. Yield: $57 \%$ based on the $\mathrm{Cd}(\mathrm{II})$ salt. Anal. calcd for $\mathrm{C}_{12} \mathrm{H}_{8} \mathrm{~N}_{6} \mathrm{O} 4 \mathrm{Cd}$ : C, 34.93; H, 1.95; N, 20.37. Found: C, 34.91; H, 1.96; N, 20.38\%. IR (KBr, $\left.\mathrm{cm}^{-1}\right): 3082$ (w), 2986 (w), 2909 (w), 2799 (w), 1588 (s), 1561 (s), 1530 (s), 1454 (s), 1437 (s), 1390 (s), 1358 (m), 1317 (m), 1231 (m), 1196 (s), 1166 (s), 1118 (s), 1105 (m), 1063 (s), 989 (s), 920 (m), 889 (s), 833 (m), 770 (m), 742 (s), 691 (s), 661 (s).

\subsection{Synthesis of $\left[\mathrm{Cd}\left(\mathrm{H}_{2} \text { biim }\right)_{0.5}(\mathrm{ip}-\mathrm{OH})\right]_{n}$ (3)}


A mixture of $\mathrm{CdCl}_{2} \cdot 2.5 \mathrm{H}_{2} \mathrm{O}(0.1 \mathrm{mmol}, 30 \mathrm{mg}), \mathrm{H}_{2}$ biim $(0.1 \mathrm{mmol}, 10 \mathrm{mg})$ and H2ip-OH $(0.1 \mathrm{mmol}, 20 \mathrm{mg})$ and $\mathrm{H}_{2} \mathrm{O}(8 \mathrm{~mL})$ was adjusted to $\mathrm{pH} 5.0$ with $0.05 \mathrm{~mol}$ $\mathrm{L}^{-1} \mathrm{NaOH}$ solution. It was then sealed in a $25 \mathrm{~mL}$ Teflon reactor and heated at $150{ }^{\circ} \mathrm{C}$ for $72 \mathrm{~h}$. The mixture was cooled to room temperature after $40 \mathrm{~h}$. Slightly purple crystals were obtained. Yield: $42 \%$ based on the $\mathrm{Cd}(\mathrm{II})$ salt. Anal. calcd for $\mathrm{C}_{11} \mathrm{H}_{7} \mathrm{~N}_{2} \mathrm{O}{ }_{5} \mathrm{Cd}: \mathrm{C}, 36.70 ; \mathrm{H}, 1.95 ; \mathrm{N}, 7.79$. Found: C, 36.76; H, 1.95; N, 7.80\%. IR $\left(\mathrm{KBr}, \mathrm{cm}^{-1}\right): 3461(\mathrm{~m}), 3058(\mathrm{w}), 2930(\mathrm{w}), 2866(\mathrm{w}), 1630(\mathrm{~s}), 1583(\mathrm{~s}), 1508(\mathrm{~m})$, 1397 (s), 1333 (s), 1291 (s), 1208 (m), 1165 (w), 1098 (w), 1014 (w), 859 (s), 750 (s), $661(\mathrm{~m}), 428(\mathrm{w})$.

\subsection{X-ray crystallography}

Single-crystal X-ray diffraction data for complexes 1-3 were recorded on a Bruker Apex CCD diffractometer with graphite-monochromated Mo- $\mathrm{Ka}$ radiation $(\lambda=$ $0.71073 \AA$ ) at $293 \mathrm{~K}$. Empirical absorption corrections were applied using the multiscan technique. The structures were solved by direct methods and refined by full-matrix least-squares based on $F^{2}$ using SHELXL-97. All non-hydrogen atoms were refined anisotropically and the hydrogen atoms of organic ligands were located geometrically. The crystal data and structure refinements of 1-3 are summarized in Table 1. Selected bond lengths and angles are listed in Table S1, while hydrogen-bonding, $\mathrm{C}-\mathrm{H} \ldots \pi$ and $\pi \ldots \pi$ interactions in $\mathbf{1 - 3}$ are listed in Table S2, Table S3 and Table S4, respectively. 
Table 1. Crystal data and structure refinements for compounds 1-3.

\begin{tabular}{|c|c|c|c|}
\hline Compound & 1 & 2 & 3 \\
\hline Empirical Formula & $\mathrm{C}_{12} \mathrm{H}_{8} \mathrm{~N}_{6} \mathrm{O}_{4} \mathrm{Zn}$ & $\mathrm{C}_{12} \mathrm{H}_{8} \mathrm{~N}_{6} \mathrm{O}_{4} \mathrm{Cd}$ & $\mathrm{C}_{11} \mathrm{H}_{7} \mathrm{~N}_{2} \mathrm{O}_{5} \mathrm{Cd}$ \\
\hline Formula Weight & 365.63 & 412.65 & 359.60 \\
\hline$T(\mathrm{~K})$ & $293(2)$ & $293(2)$ & $293(2)$ \\
\hline Wavelength $\lambda(\AA)$ & 0.71073 & 0.71073 & 0.71073 \\
\hline Crystal system & Pbca & Pbca & $P \overline{1}$ \\
\hline Space group & Orthorhombic & Orthorhombic & Triclinic \\
\hline$a(\AA)$ & $10.5585(2)$ & $10.7029(4)$ & $8.2763(8)$ \\
\hline$b(\AA)$ & $14.3946(3)$ & $14.6422(6)$ & $8.3342(8)$ \\
\hline$c(\AA)$ & $17.4888(3)$ & $17.8357(8)$ & $8.8041(14)$ \\
\hline$\alpha\left({ }^{\circ}\right)$ & 90 & 90 & $107.567(2)$ \\
\hline$\beta\left(\left(^{\circ}\right)\right.$ & 90 & 90 & $107.865(2)$ \\
\hline$\gamma\left({ }^{\circ}\right)$ & 90 & 90 & $102.6640(10)$ \\
\hline$V\left(\AA^{3}\right)$ & $2658.04(9)$ & $2795.1(2)$ & $517.48(11)$ \\
\hline$Z$ & 8 & 8 & 2 \\
\hline$D_{\text {calc }}\left(\mathrm{g} \mathrm{cm}^{-3}\right)$ & 1.827 & 1.961 & 2.308 \\
\hline$F(000)$ & 1472 & 1616 & 350 \\
\hline$R_{\text {int }}$ & 0.0219 & 0.0400 & 0.0176 \\
\hline GOF on $F^{2}$ & 1.027 & 1.013 & 1.094 \\
\hline$R_{1}{ }^{\mathrm{a}}, w R_{2}^{\mathrm{b}}[I>2 \sigma(I)]$ & $0.0233,0.0616$ & $0.0278,0.0538$ & $0.0297,0.0778$ \\
\hline$R_{1}^{\mathrm{a}}, w R_{2}^{\mathrm{b}}$ (all data) & $0.0279,0.0639$ & $0.0459,0.0595$ & $0.0347,0.0932$ \\
\hline
\end{tabular}

${ }^{\mathrm{a}} R_{1}=\sum\left\|F_{o}|-| F_{c}\right\| / \sum\left|F_{o}\right|$.

$\left.{ }^{\mathrm{b}} w R_{2}=\sum\left\{w\left(F_{o}^{2}-F_{c}^{2}\right)^{2}\right] / \sum\left[w\left(F_{o}^{2}\right)\right]^{2}\right\}^{1 / 2}$.

\section{Results and discussion}

\subsection{Synthesis}

Three new $\mathrm{Cd}(\mathrm{II}) / \mathrm{Zn}(\mathrm{II})$ coordination polymers with a $2 \mathrm{D}$ layer or 3D framework have been synthesized under hydrothermal conditions. In order to investigate the 
effect of the dicarboxylate ligands on the coordination structures, we carried out some parallel experiments by altering the dicarboxylate ligands. Reactions of $\mathrm{H}_{2}$ biim, $\mathrm{H}_{2}$ pzdc or $\mathrm{H}_{2}$ ip- $\mathrm{OH}$ and $\mathrm{CdCl}_{2}$ in $8 \mathrm{~mL} \mathrm{H}_{2} \mathrm{O}$ at $150{ }^{\circ} \mathrm{C}$ produce crystals of 2 and 3. When $\mathrm{CdCl}_{2}$ was replaced with $\mathrm{Zn}\left(\mathrm{NO}_{3}\right)_{2}$ under the same reaction conditions, only crystals of $\mathbf{1}$ were obtained, the structure of which is isostructural with $\mathbf{2}$. The $\mathrm{pH}$ value plays an important role in the formation of the three complexes. Using $\mathrm{HCl}$ and $\mathrm{NaOH}$ solutions to adjust the $\mathrm{pH}$, higher-quality crystals can be obtained at a $\mathrm{pH}$ value of 5. However, much precipitation or a clear solution for compounds 1-3 comes into being at other $\mathrm{pH}$ values. In addition, we also performed a series of parallel experiments to change the reaction temperatures, and to vary the solvent types and ratios. Unfortunately, the other experiments gave powder forms or very small crystals, which were not suitable for X-ray diffraction studies.

\section{$<$ Insert Scheme $2>$}

\subsection{Description of the crystal structures}

\subsubsection{Crystal structures of $\left[\mathrm{Zn}\left(\mathrm{H}_{2} \text { biim }\right)(\mathrm{pzdc})\right]_{n}(\mathbf{1})$ and $\left[\mathrm{Cd}\left(\mathrm{H}_{2} b i \mathrm{im}\right)(\mathrm{pzdc})\right]_{n}$ (2)}

Complexes $\mathbf{1}$ and $\mathbf{2}$ are isostructural, and hence only the structure of $\mathbf{1}$ is discussed here. There exists one $\mathrm{Zn}(\mathrm{II})$ ion, one pzdc ${ }^{2-}$ ligand and one $\mathrm{H}_{2}$ biim ligand in the asymmetric unit of $\mathbf{1}$. Each $\mathrm{Zn}(\mathrm{II})$ ion is surrounded by three oxygen atoms (O1, O2\#1, O4\#2) of three distinct pzdc ${ }^{2-}$ ligands, two nitrogen atoms $(\mathrm{N} 2, \mathrm{~N} 4)$ of one $\mathrm{H}_{2}$ biim ligand and one nitrogen atom $(\mathrm{N} 5 \# 2)$ of one pzdc- ligand, displaying a octahedral geometry (Figure. 1(a)). The $\mathrm{Zn}-\mathrm{N}$ and $\mathrm{Zn}-\mathrm{O}$ bond distances are in the ranges 2.0824(16)-2.3796(17) and 2.0516(13)-2.1638(13) Å (Table S1), respectively, which 
are comparable to similar zinc compounds [27]. In 1, the $\mathrm{H}_{2}$ biim ligands, acting as neutral chelating ligands, are located on opposite sides of the layer (Scheme 3(a), Figure. 2(c)). Each pzdc ${ }^{2-}$ ligand employ its carboxylate groups and one pyrazine nitrogen atom to coordinate to three $\mathrm{Zn}$ (II) ions. The two carboxylate groups adopt bis-mondentate and monodentate coordination modes. Therefore, the pzdc ${ }^{2-}$ ligand shows a $\mu_{3}-\eta^{1}: \eta^{1}: \eta^{1}: \eta^{1}$ coordination mode. The two carboxylate groups are out of the plane of the linking pyrazine ring, with the dihedral angles being 10.503 and $68.776^{\circ}$. Interestingly, two carboxylate groups from two different $\mathrm{pdc}^{2-}$ ligands bridge two $\mathrm{Zn}(\mathrm{II})$ ions to form a binuclear unit, $\mathrm{Zn}_{2}(\mathrm{pzdc})_{4}\left(\mathrm{H}_{2} \text { biim }\right)_{2}$ (Figure. 1(b)). The binuclear unit is an 8 -membered $\left[\mathrm{Zn}_{2} \mathrm{C}_{2} \mathrm{O}_{4}\right]$ ring with a $\mathrm{Zn} \cdots \mathrm{Zn}$ distance of $4.514 \AA$. The binuclear units are further linked by sharing $\mathrm{pzdc}^{2-}$ ligands to form a 24-membered $\left[\mathrm{Zn}_{4} \mathrm{C}_{12} \mathrm{O}_{4} \mathrm{~N}_{4}\right]$ macrocyclic ring with diagonal distances of $10.204 \times 10.987 \AA$. The rings $\mathrm{A}$ and $\mathrm{B}$ are arranged on the ab plane to form a highly ordered $2 \mathrm{D}$ layer in an ABAB sequence (Figure. 1(c)). Topologically, both the pzdc ${ }^{2-}$ ligands and the $\mathrm{Zn}(\mathrm{II})$ ions are viewed as 3-connected nodes. Thus, the $2 \mathrm{D}$ layer of $\mathbf{1}$ has a 3 -connected $\left(4.8^{2}\right)$ topology (Figure. 1(d)). The neighboring layers are linked together through

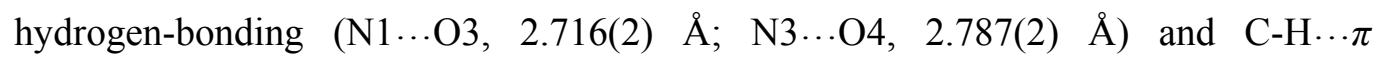
$(\mathrm{C} 7 \ldots \mathrm{Cg}(5), 3.782(2) \AA)$ interactions, resulting in a 3D supramolecular structure (Figure. 2(c), Tables S2 and S3).

\section{$<$ Insert Figs. 1 and $2>$}

\subsubsection{Crystal structure of $\left[\mathrm{Cd}\left(\mathrm{H}_{2} \text { biim }\right)_{0.5}(\mathrm{ip}-\mathrm{OH})\right]_{n}$ (3)}

Single-crystal X-ray structural analysis shows that the asymmetric unit of complex 
3 contains one $\mathrm{Cd}(\mathrm{II})$ ion, one ip- $\mathrm{OH}^{2-}$ ligand and half of a $\mathrm{H}_{2}$ biim ligand. As shown in Figure. 3(a), the $\mathrm{Cd}(\mathrm{II})$ ion is five-coordinated by four carboxylate oxygen atoms $(\mathrm{O} 1, \mathrm{O} 3 \# 1, \mathrm{O} 9 \# 3, \mathrm{O} 10 \# 2)$ from four different ip- $\mathrm{OH}^{2-}$ ligands and one nitrogen atom (N1) from one $\mathrm{H}_{2}$ biim ligand in a distorted trigonal bipyramidal coordination environment. The Cd-N bond length is 2.298(5) $\AA$ and the Cd-O bond lengths range from 2.153(4) $\AA$ to $2.504(4) \AA$ (Table S1); they are all in the normal range of bond distances [28-29]. In the structure of $\mathbf{3}$, all the carboxylate groups are deprotonated. The ip-OH- ligands, adopting a $\mu_{4}-\eta^{1}: \eta^{1}: \eta^{1}: \eta^{1}$ coordination mode, link the $\mathrm{Cd}(\mathrm{II})$ ions into a 2D undulated layer along the bc plane (Figure. 3(b)). Two carboxylate groups have a dihedral angles of $11.994^{\circ}$ and $25.747^{\circ}$ toward the plane of the corresponding linking phenyl rings. It is interesting that there exist two kinds of 8 -membered $\left[\mathrm{Cd}_{2} \mathrm{C}_{2} \mathrm{O}_{4}\right]$ rings (ring $\mathrm{A}$, ring $\mathrm{B}$ ) and two kinds of 16-membered $\left[\mathrm{Cd}_{2} \mathrm{C}_{10} \mathrm{O}_{4}\right]$ rings (ring C, ring D) in the layer, where the Cd...Cd distances vary from 4.329 to $9.714 \AA$ in the rings. The $\mathrm{H}_{2}$ biim ligands, adopting the $\mu_{2}$-bridging mode, link neighboring $2 \mathrm{D}$ layers into a 3D framework (Scheme 3(b), Figure. 3(c)). It is noteworthy that most $\mathrm{H}_{2}$ biim ligands adopt the bidentate chelating coordination mode to form coordination polymers and the $\mu_{2}$-bridging coordination mode is rare for the $\mathrm{H}_{2}$ biim ligand. As far as we know, only two examples involved the $\mu_{2}$-bridging coordination mode of the $\mathrm{H}_{2}$ biim ligand have been reported in polyoxometallates (POMs) to date [20-21]. Topologically, the $\mathrm{Cd}(\mathrm{II})$ ions and ip- $\mathrm{OH}^{2-}$ ligands are viewed as 5-connected and 4-connected nodes, respectively, and $\mathrm{H}_{2}$ biim ligands can be viewed as linkers. Therefore, the framework of complex 3 can be described as having a binodal 
$(4,5)$-connected $\left(4^{4} \cdot 6^{2}\right)\left(4^{4} \cdot 6^{6}\right)$ topology (Figure. 3(d)). In addition, hydrogen-bonding $(\mathrm{O} 2 \ldots \mathrm{O} 1,2.771(6) \AA ;$ N2 ..O $10,2.818(7) \AA \AA \mathrm{C} 2 \ldots \mathrm{O} 9,3.269(8) \AA \AA \mathrm{C} 10 \ldots \mathrm{O} 2$ 3.389(8) $\AA$ ) and $\pi \cdots \pi$ interactions $(\operatorname{Cg}(1)-\operatorname{Cg}(2), 3.708(4) \AA)$ further stabilize the 3D framework of 3 (Tables S2 and S4).

\section{$<$ Insert Fig. $3>$}

\subsection{Effects of the carboxylate ligands on the structures}

In 1 and $\mathbf{2}$, the $\mathrm{Zn}(\mathrm{II})$ or $\mathrm{Cd}(\mathrm{II})$ ion is six-coordinated by three pzdc ${ }^{2-}$ ligands and one $\mathrm{H}_{2}$ biim ligand, while in $\mathbf{3}$, each $\mathrm{Cd}(\mathrm{II})$ ion is five-coordinated by four ip- $\mathrm{OH}^{2-}$ ligands and one $\mathrm{H}_{2}$ biim ligand. Compared with the $\mathrm{H}_{2}$ pzdc ligand, the $\mathrm{H}_{2}$ ip-OH ligand has an extra hydroxyl group on each phenyl ring. Obviously, the extra hydroxyl groups of the $\mathrm{H}_{2} \mathrm{ip}-\mathrm{OH}$ ligand will increase the steric hindrance when coordinated with the metal atoms. In addition, in 1-3 the carboxylate ligands take different kinds of coordination modes. In $\mathbf{1}$ and $\mathbf{2}$, the pzdc $2-$ ligands adopts a $\mu_{3}$-bridging mode with one carboxylate group in a $\mu 2-\eta^{1}: \eta^{1}$ coordination mode and the other in a $\mu 1-\eta^{1}: \eta^{0}$ coordination mode. Moreover, one nitrogen atom of the pyrazine ring participates in the coordination as well. The pzdc ${ }^{2-}$ ligands link three neighboring $\mathrm{Zn}(\mathrm{II})$ or $\mathrm{Cd}(\mathrm{II})$ ions to form a $2 \mathrm{D}$ layer with two kinds of rings. In $\mathbf{3}$, the ip- $\mathrm{OH}^{2-}$ ligand takes a $\mu 4$-bridging mode to link four Cd(II) ions with two carboxylate groups in the $\mu_{2}-\eta^{1}: \eta^{1}$ coordination mode. Therefore, a 2D layer containing four kinds of rings is formed. Clearly, the different coordination modes of the organic dicarboxylate ligands have an obvious effect on the structures. Taking the $\mathrm{H}_{2}$ biim ligand into consideration, a bidentate chelating coordination mode was found in $\mathbf{1}$ and $\mathbf{2}$, which 
has no contribution to the dimensions of the structures. In contrast, the $\mathrm{H}_{2}$ biim ligand adopts a $\mu_{2}$-bridging mode to link $2 \mathrm{D}$ layers into a 3D framework in $\mathbf{3}$. This result indicates that dicarboxylate ligands play an important role in altering the coordination modes of $\mathrm{H}_{2}$ biim ligands [30-31]. Also, the $\mathrm{H}_{2}$ biim ligands display different dihedral angles between the imidazole rings: $11.796^{\circ}$ for $\mathbf{1}$ and $\mathbf{2}$, and $0^{\circ}$ for $\mathbf{3}$, indicating the conformation of $\mathrm{H}_{2}$ biim ligands is adjusted on introducing the dicarboxylate ligands. The differences in dihedral angles may arise mainly from the influence of weak interactions between the $\mathrm{H}_{2}$ biim and dicarboxylate ligands. In conclusion, the introduction of suitable dicarboxylate ligands is a feasible route for tuning coordination structures.

\subsection{Photoluminescent properties}

In consideration of the excellent luminescent properties of coordination polymers with $\mathrm{d}^{10}$ transitional metals, solid state luminescent studies of the free organic ligands and complexes 1-3 were performed (Figs. S1 and S2) [32-35]. The free organic ligands emit strong fluorescence centered at 343 and $356 \mathrm{~nm}\left(\lambda_{\mathrm{ex}}=280 \mathrm{~nm}\right)$ for $\mathrm{H}_{2}$ biim, $411 \mathrm{~nm}\left(\lambda_{\mathrm{ex}}=360 \mathrm{~nm}\right)$ for $\mathrm{H}_{2}$ ip-OH and $409 \mathrm{~nm}\left(\lambda_{\mathrm{ex}}=300 \mathrm{~nm}\right)$ for $\mathrm{H}_{2}$ pzdc. Usually, the emission peaks may be assigned to $\pi^{*} \rightarrow \pi$ or $\pi^{*} \rightarrow n$ transitions, as previously reported [36]. For complexes 1-3, their corresponding emission peaks were observed at $496 \mathrm{~nm}\left(\lambda_{\mathrm{ex}}=360 \mathrm{~nm}\right), 473 \mathrm{~nm}\left(\lambda_{\mathrm{ex}}=370 \mathrm{~nm}\right)$ and $449 \mathrm{~nm}\left(\lambda_{\mathrm{ex}}=360\right.$ $\mathrm{nm})$. In terms of the nature of the $\mathrm{Cd}(\mathrm{II})$ or $\mathrm{Zn}(\mathrm{II})$ ions being difficult to oxidize or reduce, the emissions of these compounds are neither metal-to-ligand charge transfer (MLCT) nor ligand-to-metal charge transfer (LMCT) [37-39]. For complex 3, a 
similar emission is observed compared to the free $\mathrm{H}$ 2ip-OH ligand, which may be attributed to intraligand transitions of the $\mathrm{H}_{2}$ ip- $\mathrm{OH}$ ligands [40]. For complexes 1 and 2, the emissions are highly red-shifted relative to the organic ligands, which can probably be assigned to intraligand transitions, admixing with ligand-to-ligand charge transitions (LLCT) [41]. The observed red shift of the emission maximum with respect to the free ligands may largely originate from the coordination of the ligands to the metal ions [42].

\subsection{Thermal analyses}

Thermogravimetric analysis was carried out for complexes 1-3 in order to investigate their thermal stability (Fig. S3). The thermogravimetric curves of complexes 1-3 are similar, which indicate they have similar weight loss processes. The complexes are thermally stable up to $248^{\circ} \mathrm{C}$ for $1,348{ }^{\circ} \mathrm{C}$ for 2 , and $326^{\circ} \mathrm{C}$ for 3 . Further weight loss indicates the decomposition of the coordination framework. The majority of weight loss is $80.26 \%$ (calc. $82.05 \%$ ) for $\mathbf{1}$ between 248 and $695{ }^{\circ} \mathrm{C}$, $70.83 \%$ (calc. $72.70 \%$ ) for 2 between 348 and $667{ }^{\circ} \mathrm{C}$, and $66.39 \%$ (calc. $68.68 \%$ ) for 3 between 326 and $682{ }^{\circ} \mathrm{C}$, which can be attributed to the decomposition of the organic components. The weights of the remaining products are $19.74 \%$ (calc. $22.15 \%$ ) for $\mathbf{1}, 29.17 \%$ (calc. $31.11 \%$ ) for 2 and $33.61 \%$ (calc. $35.59 \%$ ) for 3 . These results are consistent with formation of $\mathrm{ZnO}$ or $\mathrm{CdO}$ as the final residue.

\subsection{Powder X-ray diffraction}

Powder X-ray diffraction (PXRD) has been used to check the phase purity of these complexes in the solid state (Fig. S4). The peak positions of the measured 
PXRD patterns are in good agreement with the simulated patterns, which testify the synthesized materials and the measured single crystals are the same.

\section{Conclusion}

In summary, three coordination polymers based on the $\mathrm{H}_{2}$ biim and organic dicarboxylate ligands have been synthesized under hydrothermal conditions. They were formed under similar reaction conditions but with different dicarboxylate ligands. These complexes show a structural transition from 2D layer to 3D framework with different topologies. The results indicate that carboxylate ligands have an important effect on tuning coordination structures. The fluorescent properties of the complexes imply that they may be good candidates for optical materials. Further studies on modulating the structures of coordination polymers are underway.

\section{Acknowledgments}

This work was supported by the NSF of China $(21271038,21071027)$, the China High-Tech Development 863 Program (2007AA03Z218) and analysis and testing foundation of Northeast Normal University. 


\section{References}

[1] B. Moulton, M.J. Zaworotko, Chem. Rev. 101 (2001) 1629-1658.

[2] S. Noro, R. Kitaura, M. Kondo, S. Kitagawa, T. Ishii, H. Matsuzaka, M. Yamashita, J. Am. Chem. Soc. 124 (2002) 2568-2583.

[3] O.M. Yaghi, G.M. Li, H.L. Li, Nature 378 (1995) 703-706.

[4] M. Kondo, M. Shimamura, S. Noro, S. Minakoshi, A. Asami, K. Seki, S. Kitagawa, Chem. Mater. 12 (2000) 1288-1299.

[5] J.M. Falkowski, S. Liu, C. Wang, W.B. Lin, Chem. Commun. 48 (2012) 6508-6510.

[6] J.M. Falkowski, C. Wang, S. Liu, W.B. Lin, Angew. Chem., Int. Ed. 50 (2011) $8674-8678$.

[7] J. An, C.M. Shade, D.A. Chengelis-Czegan, S. Petoud, N.L. Rosi, J. Am. Chem. Soc. 133 (2011) 1220-1223.

[8] Y.J. Cui, H. Xu, Y.F Yue, Z.Y. Guo, J.C. Yu, Z.X. Chen, J.K. Gao, Y. Yang, G.D. Qian, B.L. Chen, J. Am. Chem. Soc. 134 (2012) 3979-3982.

[9] L.F. Ma, M.L. Han, J.H. Qin, L.Y. Wang, M. Du, Inorg. Chem. 51 (2012) 9431-9442.

[10] J. Zhou, J.W. Zhao, Q. Wei, J. Zhang, G.Y. Yang, J. Am. Chem. Soc. 136 (2014) $5065-5071$.

[11] S. Parshamoni, S. Sanda, H.S. Jena, K. Tomar, S. Konar, Cryst. Growth Des. 14 (2014) 2022-2033.

[12] B. Liu, L. Wei, N.N. Li, W.P. Wu, H. Miao, Y.Y. Wang, Q.Z. Shi, Cryst. Growth 
Des. 14 (2014) 1110-1127.

[13] W. Meng, Z.Q. Xu, J. Ding, D.Q. Wu, X. Han, H.W. Hou, Y.T. Fan, Cryst. Growth Des. 14 (2014) 730-738.

[14] C.K. Xia, C.Z. Lu, D.Q. Yuan, Q.Z. Zhang, X.Y. Wu, S.C. Xiang, J.J. Zhang, D.M. Wu, CrystEngComm 8 (2006) 281-291.

[15] H. Jin, Y.F. Qi, E.B. Wang, Y.G. Li, X.L. Wang, C. Qin, S. Chang, Cryst. Growth Des. 6 (2006) 2693-2698.

[16] Z.Y. Shi, J. Peng, Y.G. Li, Z.Y. Zhang, X. Yu, K. Alimajea, X. Wang, CrystEngComm 15 (2013) 7583-7588.

[17] B.B. Ding, Y.Q. Weng, Z.W. Mao, C.K. Lam, X.M. Chen, B.H. Ye, Inorg. Chem. 44 (2005) 8836-8845.

[18] H.J. Mo, Y.R. Zhong, M.L. Cao, Y.C. Ou, B.H. Ye, Cryst. Growth Des. 9 (2009) 488-496.

[19] Z.L. Li, Y. Wang, L.C. Zhang, J.P. Wang, W.S. You, Z.M. Zhu, Dalton Trans. 43 (2014) 5840-5846.

[20] Z.Y. Shi, J. Peng, Y.G. Li, Z.Y. Zhang, X. Yu, K. Alimaje, X. Wang, CrystEngComm 15 (2013) 7583-7588.

[21] Z.Y. Shi, J. Peng, X. Yu, Y. Shen, Z.Y. Zhang, K. Alimaje, X. Wang, Inorg. Chem. Commun. 28 (2013) 85-89.

[22] J. Kim, B.L. Chen, T.M. Reineke, H.L. Li, M. Eddaoudi, D.B. Moler, M. O’Keeffe, O.M. Yaghi, J. Am. Chem. Soc. 123 (2001) 8239-8247.

[23] Y.J. Mu, G. Han, Z. Li, X.T. Liu, H.W. Hou, Y.T. Fan, Cryst. Growth Des. 12 
(2012) 1193-1200.

[24] Y.Q. Yang, J. Yang, W.Q. Kan, Y. Yang, J. Guo, J.F. Ma, Eur. J. Inorg. Chem. 2013 (2013) 280-292.

[25] X. He, X.P. Lu, M.X. Li, R.E. Morris, Cryst. Growth Des. 13 (2013) 1649-1654.

[26] E.E. Bernarducci, P.K. Bharadwaj, R.A. Lalancette, K.K. Jespersen, J.A. Potenza, H.J. Schugar, Inorg. Chem. 22 (1983) 3911-3920.

[27] Y. Yang, P. Du, J.F. Ma, W.Q. Kan, B. Liu, J. Yang, Cryst. Growth Des. 11 (2011) $5540-5553$.

[28] J. Chakraborty, B. Samanta, G. Pilet, S. Mitra, Inorg. Chem. Commun. 10 (2007) $40-44$.

[29] S.C. Goel, M.Y. Chiang, W.E. Buhro, J. Am. Chem. Soc. 112 (1990) 6724-6125.

[30] L.M. Fan, W.L. Fan, W.K. Song, L.M. Sun, X. Zhao, X.T. Zhang, Dalton Trans. 43 (2014) 15979-15989.

[31] Z.H. Yan, L.L. Han, Y.Q. Zhao, X.Y. Li, X.P. Wang, L. Wang, D. Sun, CrystEngComm 16 (2014) 8747-8755.

[32] P.C. Ford, E. Cariati, J. Bourassa, Chem. Rev. 99 (1999) 3625-3647.

[33] V.W.W. Yam, K.K.W. Lo, Chem. Soc. Rev. 28 (1999) 323-334.

[34] J. Tao, M.L. Tong, J.X. Shi, X.M. Chen, S.W. Ng, Chem. Commun. (2000) 2043-2044.

[35] S.C. Chen, R.M. Yu, Z.G. Zhao, S.M. Chen, Q.S. Zhang, X.Y. Wu, F. Wang, C.Z. Lu, Cryst. Growth Des. 10 (2010) 1155-1160.

[36] Y.Y. Liu, B. Liu, J. Yang, J.F. Ma, Polyhedron 56 (2013) 96-101. 
[37] J.Y. Sun, L. Wang, D.J. Zhang, D. Li, Y. Cao, L.Y. Zhang, S.L. Zeng, G.S. Pang, Y. Fan, J.N. Xu, T.Y. Song, CrystEngComm 15 (2013) 3402-3411.

[38] D. Niu, J. Yang, J. Guo, W.Q. Kan, S.Y. Song, P. Du, J.F. Ma, Cryst. Growth Des. 12 (2012) 2397-2410.

[39] X.F. Zhu, N. Wang, X.Y. Xie, R.B. Hou, D.F. Zhou, Y.F. Li, J. Hu, X.Y. Li, H. Liu, W. Nie, RSC Adv. 4 (2014) 15816-15819.

[40] X.D. Guo, G.S. Zhu, Z.Y. Li, Y. Chen, X.T. Li, S.L. Qiu, Inorg. Chem. 45 (2006) $4065-4070$.

[41] W.Q. Kan, J. Yang, Y.Y. Liu, J.F. Ma, CrystEngComm 14 (2012) 6271-6281.

[42] D. Sun, L.L. Han, S. Yuan, Y.K. Deng, M.Z. Xu, D.F. Sun, Cryst. Growth Des. 13 (2013) 377-385. 


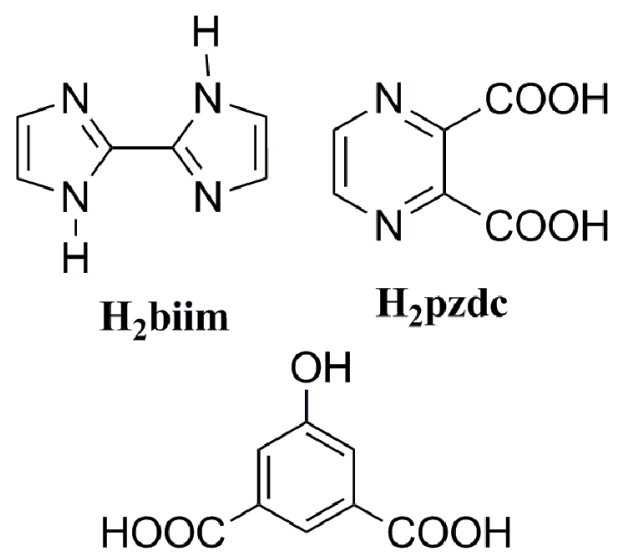

\section{$\mathrm{H}_{2} \mathbf{i p}-\mathrm{OH}$}

Scheme 1. Schematic representation of the organic ligands. 


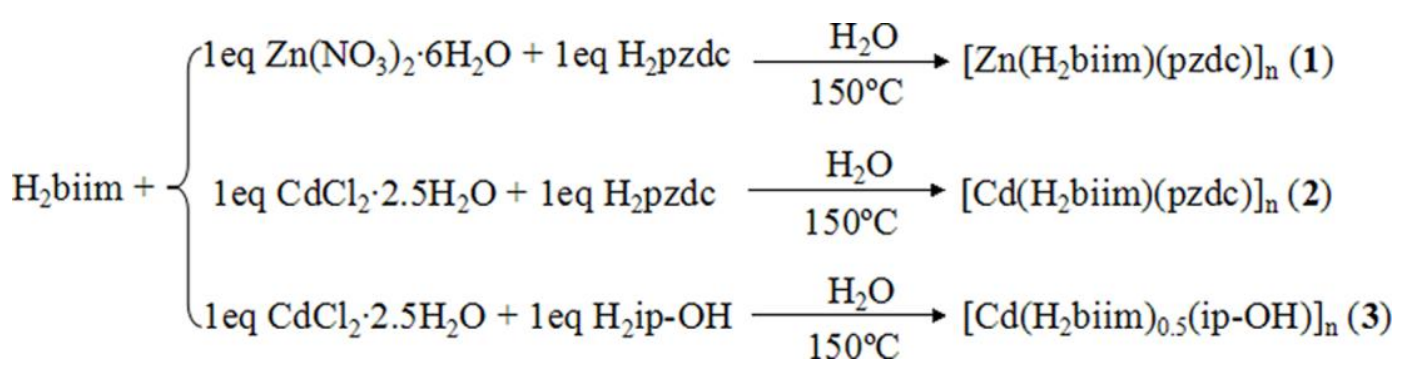

Scheme 2. Syntheses of compounds 1-3. 


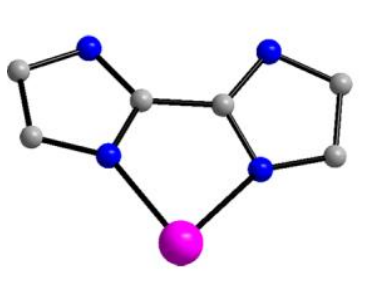

(a)

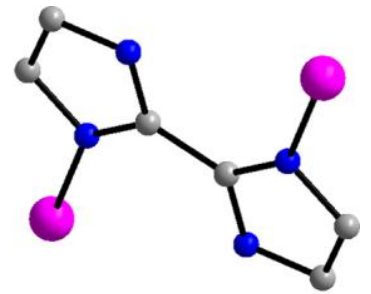

(b)

Scheme 3. Coordination modes of the $\mathrm{H}_{2}$ biim ligand found in compounds 1-3. 

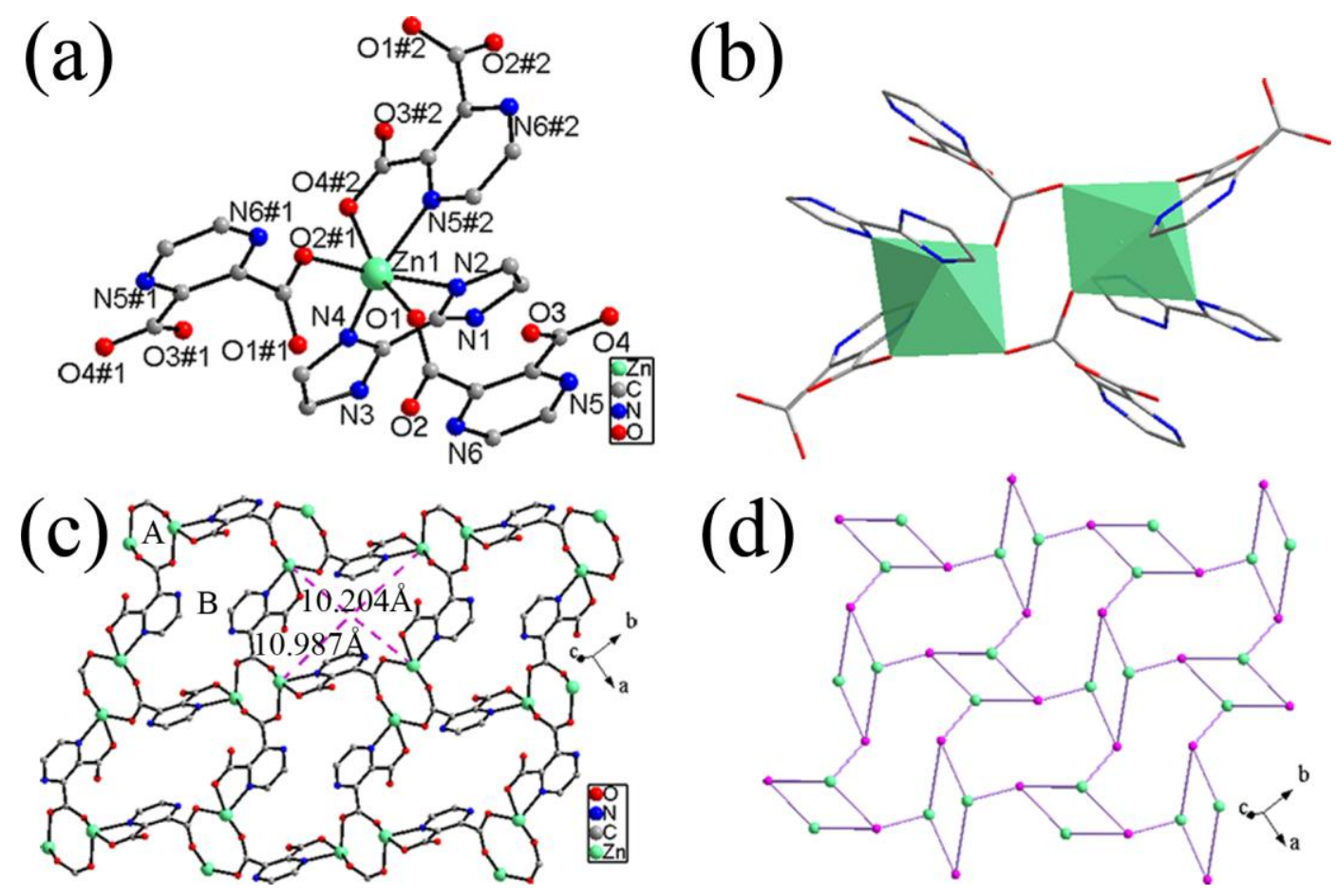

Fig. 1 (a) Coordination environment of the $\mathrm{Zn}(\mathrm{II})$ ion in $\mathbf{1}$ (Symmetry codes: \#1: $-\mathrm{x}+1$, $-y+1,-z+1 ; \# 2: x+1 / 2,-y+1 / 2,-z+1$. All hydrogen atoms are omitted for clarity). (b) View of the binuclear unit of $\mathbf{1}$ (c) The 2D layer of $\mathbf{1}$ with two types of rings (ring A, ring B). (d) Schematic view of the 3-connected $\left(4.8^{2}\right)$ topology of $\mathbf{1}$. 
(a)

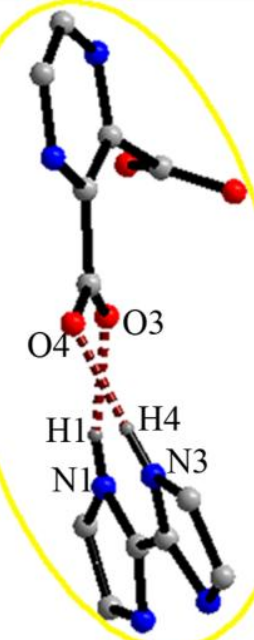

(b)

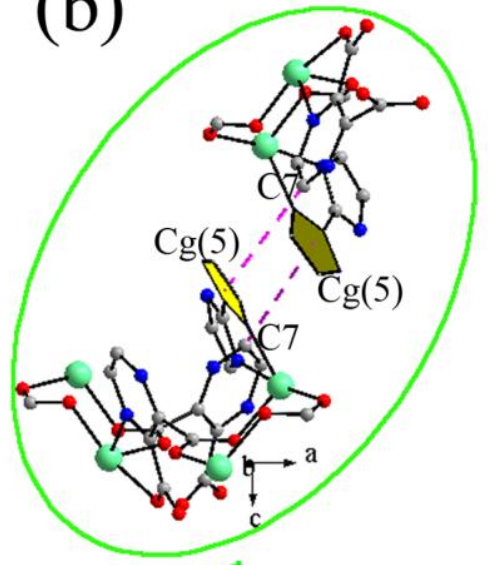

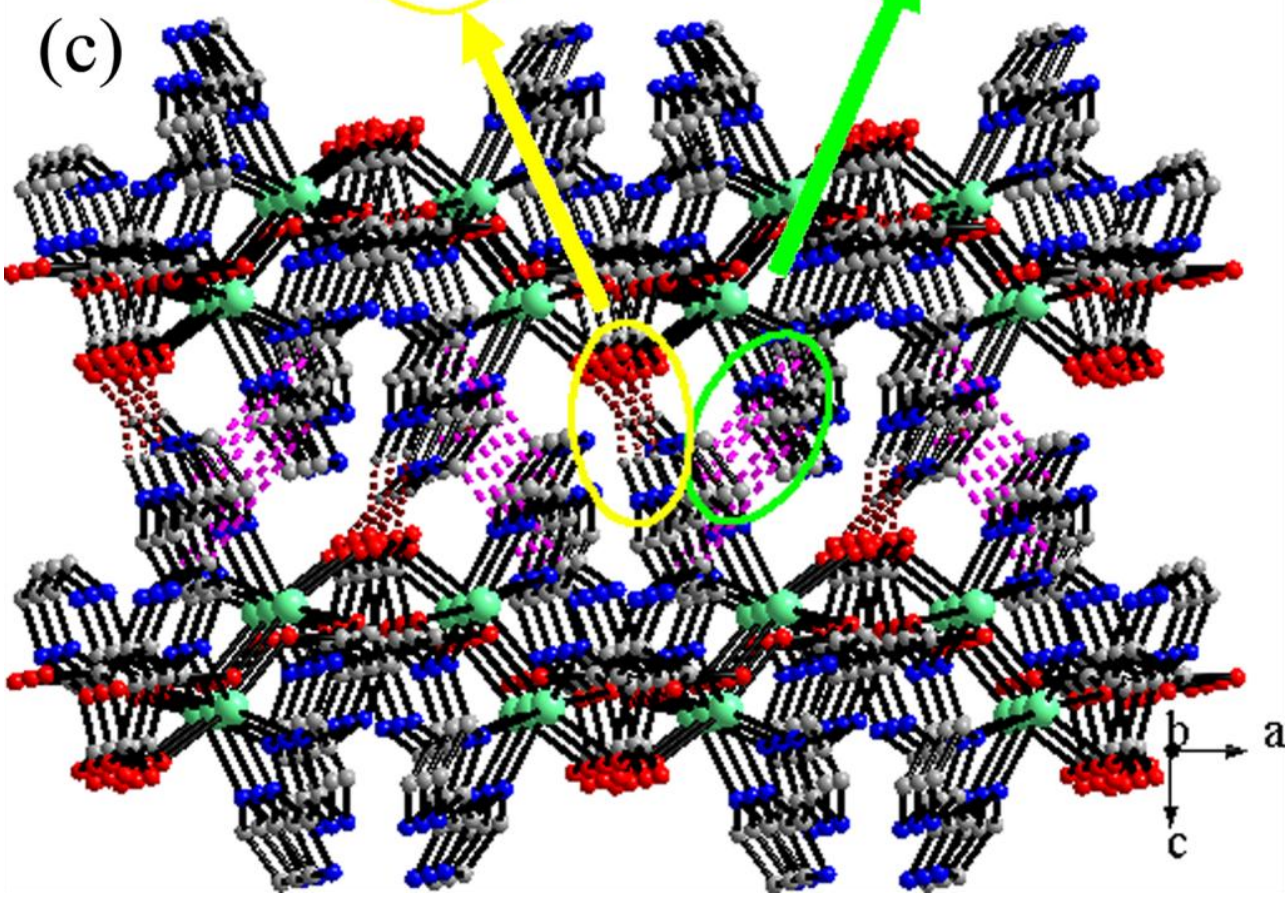

Fig. 2 (a) A partial schematic view of the hydrogen bonding interactions in 1. (b) A partial schematic view of the C-H... $\pi$ interactions in 1. (c) The 3D supramolecular framework constructed by hydrogen-bonding and C-H... $\pi$ interactions in $\mathbf{1}$. 


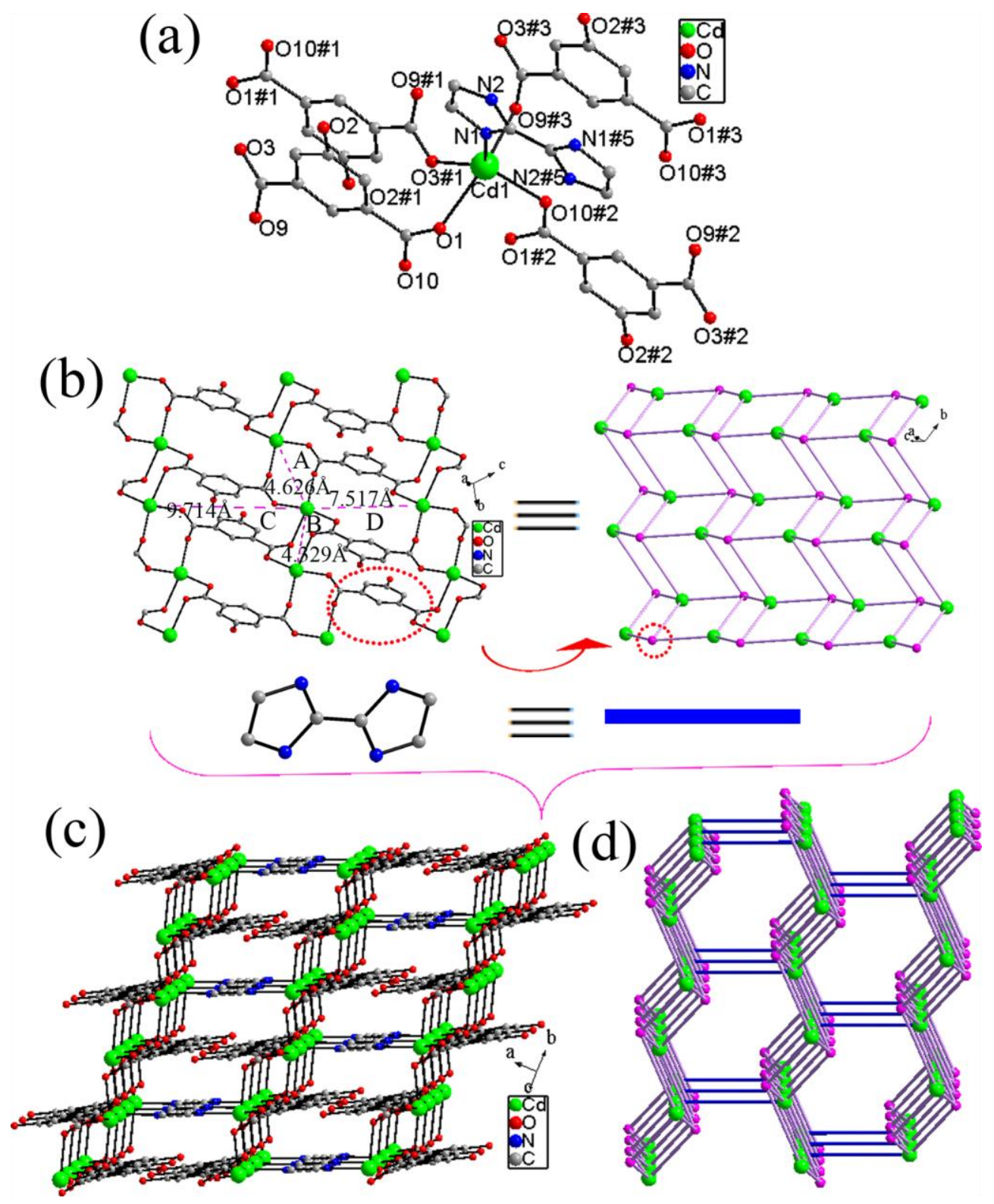

Fig. 3 (a) Coordination environment of the Cd(II) ion in $\mathbf{3}$ (Symmetry codes: \#1: -x, $-\mathrm{y},-\mathrm{z}+1$; \#2: -x, $-\mathrm{y}+1,-\mathrm{z}+2$; \#3: $\mathrm{x}, \mathrm{y}, \mathrm{z}+1 ; \# 5:-\mathrm{x}+1,-\mathrm{y}+1,-\mathrm{z}+3$. All hydrogen atoms are omitted for clarity). (b) (top) The 2D layer with four types of rings (ring A, ring B, ring $\mathrm{C}$, ring $\mathrm{D}$ ) formed by ip- $\mathrm{OH}^{2-}$ ligands and metal centers and (bottom) the $\mathrm{H}_{2}$ biim ligand acting as a linker. (c) The 3D framework of $\mathbf{3}$ formed by $\mathrm{Cd}(\mathrm{II})$ ions, ip- $\mathrm{OH}^{2-}$ and $\mathrm{H}_{2}$ biim ligands. (d) Schematic view of the 3D binodal (4,5)-connected $\left(4^{4} \cdot 6^{2}\right)\left(4^{4} \cdot 6^{6}\right)$ topology of 3 . 